\title{
Conservação de repolho minimamente processado sob efeito de diferentes embalagens, tempo de estocagem e temperatura
}

\author{
Leandro Bassi Moreno ${ }^{1}$, Rainer Scherwinski' ${ }^{1}$, João Manoel Teixeira da Silva ${ }^{1}$, Silvana de \\ Paula Quintão Scalon ${ }^{1}$, Thiago Oliveira Carnevalli ${ }^{1}$
}

\begin{abstract}
${ }^{1}$ Universidade Federal da Grande Dourados, Dourados, Mato Grosso do Sul, Brasil. E-mail: leandrobmoreno@ hotmail.com, rainer_scherwinski@hotmail.com, jinoteixeira@hotmail.com, silvanascalon@ufgd.edu.br, thiagocarnevali@live.com
\end{abstract}

Recebido: 18/05/2016; Aceito: 28/06/2016.

\section{RESUMO}

A utilização de atmosfera modificada e redução da temperatura de armazenamento aumentam a vida útil de diversas hortaliças e frutas minimamente processadas. O presente estudo consistiu em avaliar os efeitos de diferentes embalagens, temperaturas e tempo de estocagem $(0,4,8$ e 12 dias) nas propriedades físico-químicas de repolho minimamente processado. As amostras foram acondicionadas em bandeja pet, bandeja de isopor embaladas com filme PVC e em sacos plásticos sob diferentes temperaturas $\left(8{ }^{\circ} \mathrm{C}, 1{ }^{\circ} \mathrm{C}\right.$ e $\left.25{ }^{\circ} \mathrm{C}\right)$, que foram arranjados em esquema fatorial $3 \times 3$, no delineamento experimental de blocos inteiramente casualizados, com três repetições. Após o processamento do repolho foram retiradas $150 \mathrm{~g}$ do material e acondicionado nas diferentes embalagens. De modo geral, observou-se que, independente do tipo de embalagem utilizada, as amostras armazenadas a $15{ }^{\circ} \mathrm{C}$ apresentaram os melhores resultados para todas as variáveis analisadas. Este efeito pode ser creditado ao efeito positivo da baixa temperatura na diminuição da concentração de oxigênio e gás carbônico, que em geral, é essencial para a conservação das propriedades físico-químicas do repolho minimamente processado.

Palavras-chave: Brassica oleracea var. capitata, pós-colheita, conservação.

\section{Conservation of minimally processed cabbage under the effect of different packaging, storage time and temperature}

\begin{abstract}
The use of modified atmosphere and low storage temperature can increase the useful life of various minimally processed vegetables and fruits. This study was designed to evaluate the effects of different packaging, temperature and storage time $(0,4,8$ and 12 days) on the physicochemical properties of minimally processed cabbage. The samples were placed in pet tray, styrofoam tray packed with plastic wrap and plastic bags under different temperatures $\left(8,15\right.$ and $\left.25{ }^{\circ} \mathrm{C}\right)$. Treatments were arranged in a factorial $3 \times 3$, experimental design complete randomized block design with three replications. After the cabbage processing were taken $150 \mathrm{~g}$ of the material and packaged in different packages. In general, it was observed that, regardless of the type of packaging used, samples stored at $15{ }^{\circ} \mathrm{C}$ showed the best results for all variables. This effect can be attributed to the positive effect of low temperature to decrease the concentration of oxygen and carbon dioxide, which in general is essential to the conservation of the physicochemical properties of minimally processed cabbage.
\end{abstract}

Key words: Brassica oleracea var. capitata, post harvest, storage. 


\section{Introdução}

O repolho (Brasica oleracea var. capitata) é a variedade botânica de maior importância econômica no mundo, sendo, no Brasil, a brassica mais consumida (SOARES et al., 2009). Os produtos minimamente processados surgiram para dar resposta a uma nova tendência de consumo e têm tido uma aceitação cada vez maior nos mercados mundiais. As frutas e hortaliças processadas atraem os consumidores que procuram produtos frescos e saudáveis, e que também sejam adequados para o transporte e preparo (SANTOS; OLIVEIRA, 2012). A alta demanda tem levado a um aumento na quantidade, qualidade e variedade de produtos disponíveis para o consumidor (JACXSENS et al., 2002).

Para que a hortaliça "in natura" seja modificada fisicamente sendo um produto minimamente processado é necessário diversas operações que protejam essas matérias primas de danos físicos e mecânicos, de contaminação microbiológica, física e por insetos. Frequentemente esses problemas ocorrem devido ao manuseio impróprio da matéria prima e da falta de higiene dos manipuladores (EMBRAPA, 2011).

$\mathrm{O}$ processamento mínimo inclui, geralmente, as etapas de seleção da matéria-prima, pré-lavagem, processamento (descascamento e corte), sanificação, enxágue, centrifugação e embalagem (SANTOS et al., 2010). A centrifugação é uma etapa importante durante o processamento mínimo pois é a forma de retirar o excesso de líquido proveniente das etapas de sanificação e enxágue, além dos exsudados celulares resultantes do corte, os quais favorecem o crescimento de fungos e de bactérias (SILVA; GUERRA, 2003).

A utilização de atmosfera modificada e redução da temperatura de armazenamento aumentam a vida útil de diversas hortaliças e frutas minimamente processadas (TELES et al., 2005). Atmosferas entre 2 a $8 \%$ de $\mathrm{O}_{2}$ e 5 a $15 \%$ de $\mathrm{CO}_{2}$ têm potencial para aumentar a vida útil e viabilizar a comercialização destes produtos. Porém, para cada vegetal existe uma atmosfera específica que maximiza sua durabilidade (CANTWELL; SUSLOW, 2002). Para o repolho minimamente processado, a temperatura indicada para a conservação varia de 0 a $5^{\circ} \mathrm{C}$ (CANTWELL; SUSLOW, 2002) e a ótima concentração de $\mathrm{O}_{2}$ está entre 2,2 e 4,3\% (KAWANO et al., 1984).

Diante do exposto, este trabalho objetivou avaliar os efeitos de diferentes embalagens, temperatura e tempo de estocagem do repolho minimamente processado da variedade sooshu.

\section{Material e Métodos}

O trabalho foi realizado no laboratório da Faculdade de Ciências Agrárias - FCA, na Universidade Federal da Grande Dourados - UFGD, em Dourados - MS, entre 27 de abril a 11 de maio de 2015. O repolho híbrido da variedade sooshu, foi obtido de uma plantação comercial localizada em Dourados, MS. As cabeças de repolho encontravam-se no ponto ótimo de maturidade hortícola, ou seja, completamente formada e desenvolvidas, apresentando-se compactas e com folhas bem imbricadas e idade média de 60 dias de campo. Após colhidas, as cabeças foram pré-resfriadas para a perda do calor de campo, e acondicionadas em caixas plásticas para o transporte até o laboratório.

As cabeças foram selecionadas, descartando-se, folhas externas (superficiais), operação conhecida como toalete do produto, e as que apresentavam qualquer indício de dano proveniente do ataque de pragas e doenças. O repolho foi lavado em água corrente e colocadas em bacias plásticas previamente higienizadas, sendo em seguida submetidas ao processamento mínimo. Foram realizados corte manual dos repolhos em duas partes e feito o fatiamento em tiras de $\pm 3 \mathrm{~mm}$ de espessura, utilizando-se faca de aço inoxidável afiada. A temperatura do ambiente foi mantida a $15 \pm 3^{\circ} \mathrm{C}$ e todas as pessoas envolvidas no processamento utilizaram Equipamento de Proteção Individual (EPI), que constou de avental, touca, máscara e luvas.

Após o processamento do repolho, foram retiradas $150 \mathrm{~g}$ do material e acondicionado em três tipos de embalagem: embalagens de tereftalato de polietileno 0,5 mm (PET), com tampa; bandejas de isopor, revestidas com filme flexível de policloreto de vinila $10 \mu \mathrm{m}$ (PVC) e sacos plásticos $20 \mu \mathrm{m}$. Em seguida as bandejas foram armazenadas em câmaras frias nas seguintes temperaturas $8{ }^{\circ} \mathrm{C}, 15^{\circ} \mathrm{C}$ e $25^{\circ} \mathrm{C}$. Os tratamentos foram arranjados em esquema fatorial $3 \times 3$, em delineamento experimental inteiramente casualizado, com três repetições.

Os tratamentos foram analisados nos tempos, $0,4,8$, e 12 dias após o armazenamento sendo estes arranjados em parcelas subdivididas no tempo. Em cada época de avaliação, as embalagens foram retiradas dos ambientes e pesadas em balança analítica para a determinação da perda de matéria fresca. Os teores de sólidos solúveis, $\mathrm{pH}$, acidez titulável e vitamina $\mathrm{C}$ foram obtidos por medições feitas no suco de folhas de repolho, com adição de $30 \mathrm{~mL}$ de água destilada e trituradas com auxílio de liquidificador.

$\mathrm{O}$ pH foi determinado diretamente pela imersão do eletrodo do peagâmetro, o aparelho utilizado foi o da marca Hanna Instruments, modelo HI 2221. O teor de sólidos solúveis foi determinado, utilizando-se refratômetro digital da marca Instrutherm, modelo RTD-45, sendo o resultado expresso em ${ }^{\circ}$ Brix, com valor corrigido para $25{ }^{\circ} \mathrm{C}$. A acidez titulável foi determinada conforme Instituto Adolfo Lutz (1985) utilizando-se peagâmetro. Pesou-se $10 \mathrm{~g}$ da amostra em 
um béquer e adicionou-se $90 \mathrm{~mL}$ de água destilada. Titulou-se com solução de hidróxido de sódio $0,01 \mathrm{~N}$ até o $\mathrm{pH}$ atingir 8,1. Os resultados foram expressos em porcentagem de ácido cítrico, ou seja, gramas de ácido cítrico/100 gramas de amostra do produto (repolho). Os níveis de vitamina $\mathrm{C}$ determinados segundo metodologia de Tillmans (Instituto Adolfo Lutz) a qual se baseia na redução do indicador 2,6 dicloro-benzeno indofenol (DCFI) pelo ácido ascórbico, sendo expresso como mg ácido ascórbico / $100 \mathrm{~g}$ de produto.

As médias dos dados obtidos foram submetidas à análise de variância e quando verificada significância pelo teste $\mathrm{F}$, foram ajustadas equações de regressão em função das épocas de avaliação, a 5\% de probabilidade. Os dados expressos em porcentagem foram transformados em arco seno de $(x / 100)^{0,5}$, para a realização das análises estatísticas, utilizando o programa computacional (SAEG).

\section{Resultados e Discussão}

Todas as características avaliadas foram influenciadas significativamente pelos fatores embalagens e temperaturas nas diferentes épocas de avaliação. A perda acumulada de massa de repolho foi incrementada com o aumento do tempo de armazenamento (Figura 1). No entanto, observou-se que a menor perda de massa foi obtida com o armazenamento em temperatura de $8{ }^{\circ} \mathrm{C}$, com nédia de $4,65 \%$, sendo menor que a perda apresentada nas amostras armazenadas a $25{ }^{\circ} \mathrm{C}$. A perda de massa em função da embalagem foi maior na embalagem saco plástico $(57,71 \mathrm{~g})$, seguida pela bandeja isopor e bandeja pet $(23,35 \mathrm{~g}$ e 22,66 g) respectivamente, armazenadas a $25{ }^{\circ} \mathrm{C}$. Nas outras temperaturas de armazenamento houve pouca variação de massa utilizando as diferentes embalagens.

De modo geral, os resultados obtidos para a perda de massa acumulada foi o esperado, sendo a temperatura de armazenamento o principal fator que reduz a perda de massa, esta seguida pelo fator de armazenagem. A redução de temperatura diminui a respiração e retarda a senescência, por desacelerar o metabolismo. De acordo com (CHITARRA; CHITARRA, 2005), a temperatura tem influência direta na pressão de vapor, ocasionando a perda d'água, assim quanto mais baixa a temperatura menor é a perda.

O tempo de armazenagem limita a vida útil da hortaliça minimamente processada, segundo Luengo e Calbo (2001), o limite máximo de perda de massa para a comercialização é da ordem de $5 \%$ do peso fresco. $\mathrm{Na}$ temperatura de $8{ }^{\circ} \mathrm{C}$ houve perda máxima de $3 \%$ aos 12 dias de armazenamento. Na temperatura de $15{ }^{\circ} \mathrm{C}$ foi obtida perda de $5 \%$ até o oitavo dia de armazenamento nas embalagens bandeja pet e saco plástico, e na temperatura de $25{ }^{\circ} \mathrm{C}$ foi obtida perda de $5 \%$ até o quarto dia de armazenamento utilizando as embalagens bandeja pet e bandeja de isopor.

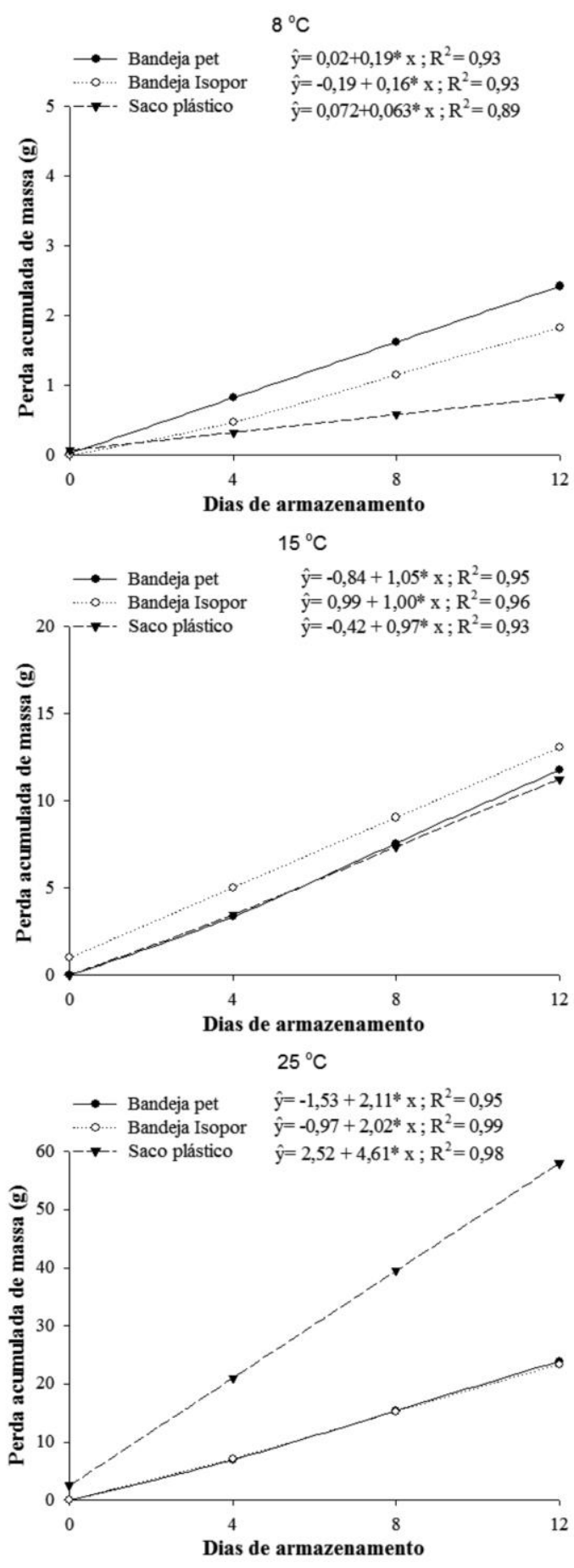

Figura 1. Porcentagem de perda acumulada de massa em repolho minimamente processado e armazenado em diferentes embalagens, temperaturas e dias de armazenamento.

O teor de sólidos solúveis totais reduziu com o tempo de armazenamento, independentemente do tipo de embalagem e temperatura armazenada (Figura 2). Para o repolho armazenado a $8{ }^{\circ} \mathrm{C}$ em saco plástico não foi ajustado regressão devido à alta variação entre as épocas de avaliação, obtendo-se média de $3,15^{\circ}$ Brix. De modo geral, o tempo de armazenamento foi o fator primordial em redução do teor de sólidos solúveis totais, 
essa característica avalia o total de substâncias dissolvidas na água sendo contabilizados teores de açúcares, sais, proteínas, ácidos entre outros sólidos. Tais substâncias proporcionam sabor ao alimento e são utilizadas pelas células para obtenção de energia, sendo assim, ao longo do tempo mais substâncias são quebradas para gerar energia e são dissolvidas na água.

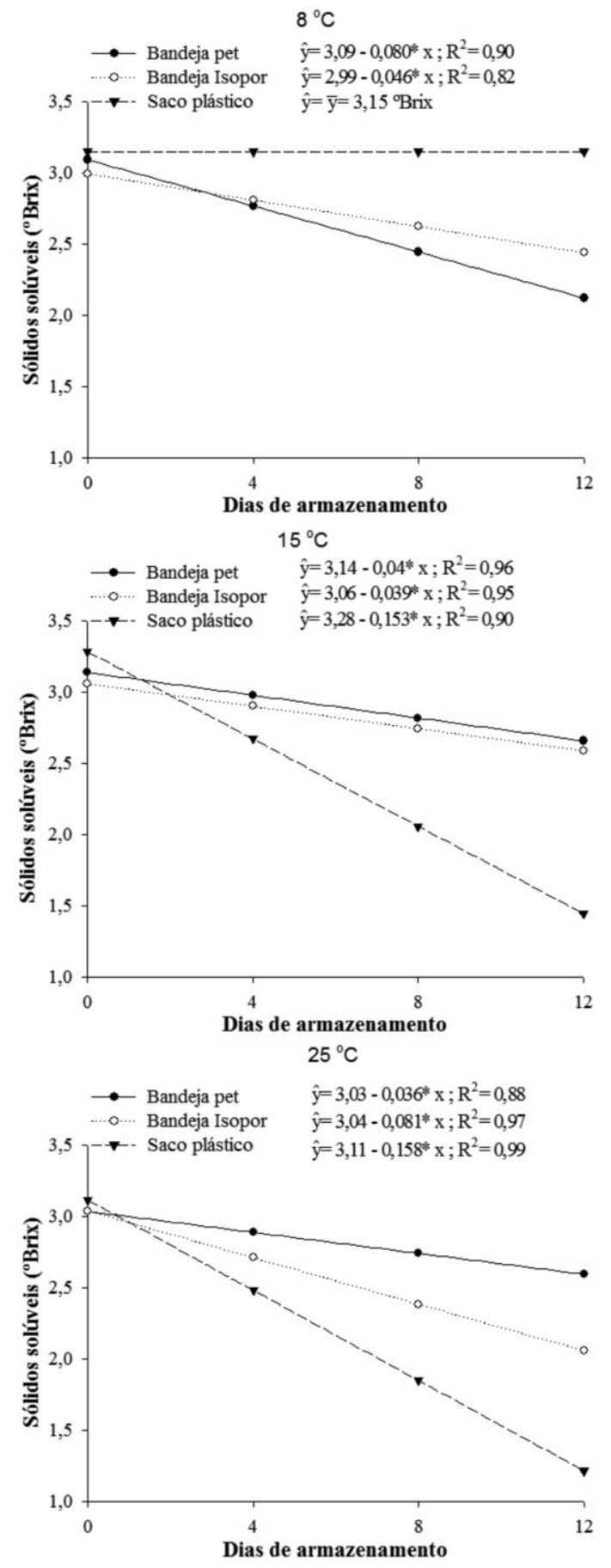

Figura 2. Sólidos solúveis em repolho minimamente processado e armazenado em diferentes embalagens, temperaturas e dias de armazenamento.

Houve redução do teor de sólidos solúveis em todas as temperaturas de armazenamento. Observou-se que a maior redução foi obtida utilizando a embalagem saco plástico de $1,9{ }^{\circ}$ Brix e a menor de $0,42{ }^{\circ}$ Brix para bandeja pet na temperatura de armazenamento de $25^{\circ} \mathrm{C}$. Quando avaliado na temperatura de $15{ }^{\circ} \mathrm{C}$ a maior redução de Sólidos Solúveis foi $1,74{ }^{\circ}$ Brix na embalagem saco plástico, e 0,43 e $0,47^{\circ}$ Brix para bandeja pet e bandeja isopor, respectivamente.

Para amostras acondicionadas em sacos plásticos e armazenas a $8{ }^{\circ} \mathrm{C}$ a média foi de $3,15{ }^{\circ}$ Brix para todos os tempos de armazenagem, diferentemente das embalagens bandeja pet e bandeja isopor que sofreram redução de 0,98 e $0,55^{\circ}$ Brix, respectivamente. Segundo (RINALDI et al., 2005), a redução nos teores de sólidos solúveis mostrou que embalagens de PVC e PET não são eficientes, na modificação da atmosfera, para garantir menos consumo de substrato de produto.

Houve redução da acidez titulável com o aumento dos dias de armazenamento em todas as embalagens e temperaturas testadas (Figura 3); observou-se menor perda de acidez nas amostras mantidas na temperatura de $15{ }^{\circ} \mathrm{C}$. O armazenamento em embalagem de bandeja pet apresentou os maiores valores de acidez titulável, no entanto, o uso da bandeja de isopor apresentou maiores reduções de acidez.

Estes resultados não são semelhantes ao encontrado por Rinaldi et al. (2005) onde observou-se que o repolho acondicionado na embalagem PVC apresentou maior acidez que o acondicionado na embalagem PET. Segundo Roura et al. (2000) logo após o processamento, o tecido vegetal apresenta maior atividade respiratória podendo haver decréscimo na acidez por consumo dos ácidos orgânicos no processo respiratório.

Em armazenamento torna-se natural a redução da acidez, visto que os ácidos orgânicos combinados com sais, ésteres e glicosídeos são importantes fontes de energia para os vegetais, sofrendo oxidação no ciclo de Krebs (KLUGE et al., 2002). As menores perdas de acidez ocorridas na temperatura de $15{ }^{\circ} \mathrm{C}$ podem estar relacionadas com a umidade do produto; estes foram valores médios de acidez titulável nessa temperatura, o que manteve a atividade respiratória maior que a de 8 ${ }^{\circ} \mathrm{C}$, aumentando a concentração de $\mathrm{CO} 2$ e reduzido a perda de acidez. Isso pode ser observado na embalagem de bandeja pet apresentando os menores valores de perdas de acidez, independente da temperatura.

$\mathrm{O} \mathrm{pH}$ do repolho minimamente processado na temperatura de $8^{\circ} \mathrm{C}$ aumentou até o oitavo dia de armazenamento, chegando ao maior valor de 6,8 para amostras em saco plástico e o menor valor de $(6,2)$, para embalagem bandeja pet (Figura 4). Na temperatura de $15{ }^{\circ} \mathrm{C}$ não houve ajuste de regressão devido à alta variação entre as épocas; os tratamentos bandeja isopor e saco plástico obtiveram média de 6,22 e 6,46, respectivamente. Para a bandeja pet, iniciou com $\mathrm{pH}$ de 5,8 e após o armazenamento de 12 dias, chegou a 6,25 . 


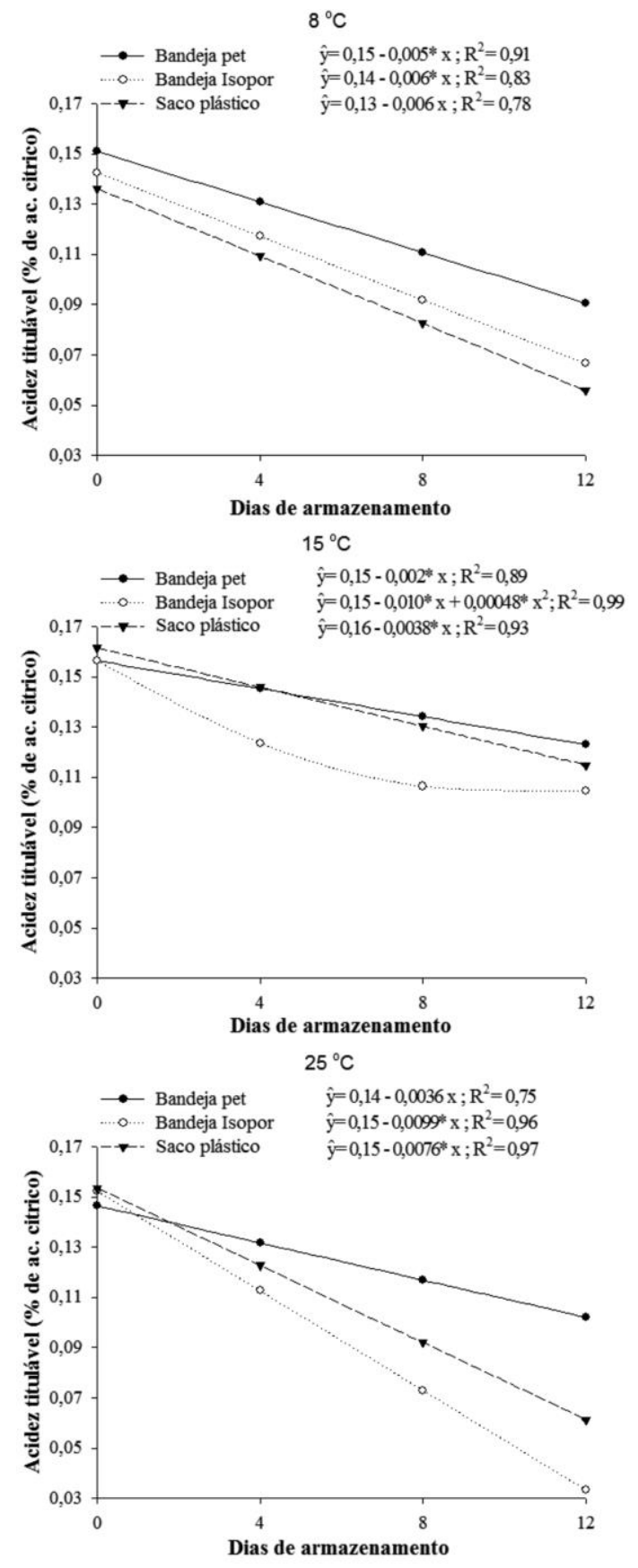

Figura 3. Acidez titulável em repolho minimamente processado e armazenado em diferentes embalagens, temperaturas e dias de armazenamento

$\mathrm{Na}$ armazenagem a $25{ }^{\circ} \mathrm{C}$, as amostras em embalagem de saco plástico alcançaram $\mathrm{pH}$ de 6,8 no quinto dia; as embaladas em bandeja de isopor alcançaram $\mathrm{pH}$ de 6,75 no sétimo dia e as bandejas pet, iniciaram com $\mathrm{pH}$ de 5,75 e ao décimo segundo dia observou-se o valor de 6,25 pH. Rinaldi et al. (2009) trabalhando com repolho minimamente processado sob diferentes sistemas de embalagem, observaram aumento do $\mathrm{pH}$ e atribuíram este aumento à população de microrganismos durante o armazenamento. $\mathrm{O}$ teor de vitamina $\mathrm{C}$ do repolho minimamente processado apresentou comportamento quadrático em função dos dias de armazenamento (Figura 5).

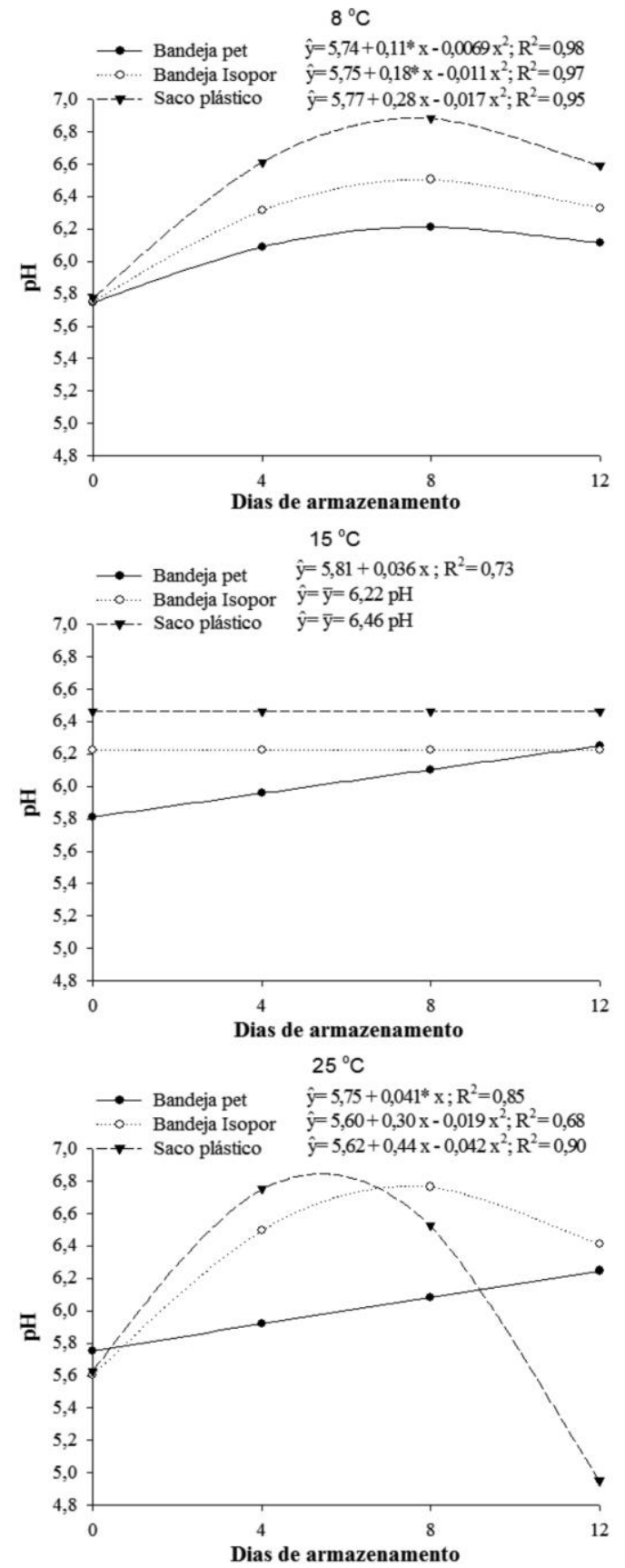

Figura 4. $\mathrm{pH}$ em repolho minimamente processado e armazenado em diferentes embalagens, temperaturas e dias de armazenamento.

$\mathrm{O} \mathrm{pH}$ do repolho minimamente processado na temperatura de $8^{\circ} \mathrm{C}$ aumentou até o oitavo dia de armazenamento, chegando ao maior valor de 6,8 para amostras em saco plástico e o menor valor de $(6,2)$, para embalagem bandeja pet (Figura 4). Na temperatura de $15{ }^{\circ} \mathrm{C}$ não houve ajuste de regressão devido à alta variação entre as épocas; os tratamentos bandeja isopor e saco plástico obtiveram média de 6,22 e 6,46, respectivamente. Para a bandeja pet, teve início com 5,8 e após o armazenamento de 12 dias, chegou a 6,25.

$\mathrm{Na}$ armazenagem a $25{ }^{\circ} \mathrm{C}$, as amostras em embalagem de saco plástico alcançaram $\mathrm{pH}$ de 6,8 no quinto dia, enquanto que as amostras embaladas em 
bandeja de isopor alcançaram pH de 6,75 no sétimo dia. Já para a bandeja pet, iniciou com pH de 5,75 e ao décimo segundo dia observou-se o valor de $6,25 \mathrm{pH}$. Rinaldi et al. (2009) trabalhando com repolho minimamente processado sob diferentes sistemas de embalagem, observaram aumento do $\mathrm{pH}$ e atribuíram este aumento à população de microrganismos durante o armazenamento.
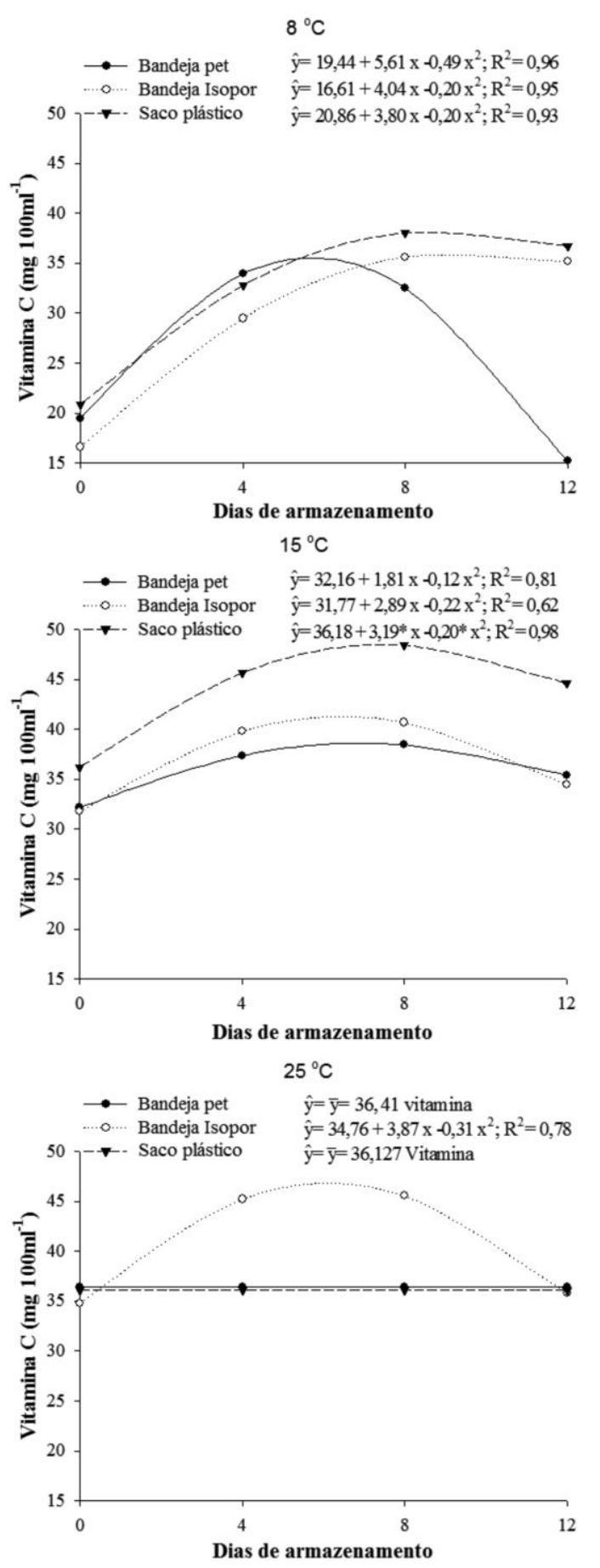

Figura 5. Teor de vitamina $\mathrm{C}$ em repolho minimamente processado e armazenado em diferentes embalagens, temperaturas e dias de armazenamento.

Para a temperatura $8{ }^{\circ} \mathrm{C}$ os valores foram crescentes até o quinto dia, com valor máximo de $35,3 \mathrm{mg} / 100 \mathrm{~mL}$
1 seguindo redução de $21 \%$ até o final do décimo segundo dia de armazenamento; para as embalagens em bandeja isopor e saco plástico os valores foram crescentes até o oitavo dia $\left(35,7\right.$ e $38,0 \mathrm{mg} / 100 \mathrm{~mL}^{-1}$, respectivamente). Ao avaliar o armazenamento de repolho minimamente processado a $5^{\circ} \mathrm{C}$., Gioppo et al. (2012) observaram que os valores de vitamina $\mathrm{C}$ foram crescentes até o nono dia, com valores médios de 2,38 $\mathrm{mg} / 100 \mathrm{~g}^{-1}$, seguindo-se redução de $5 \%$ até o final do armazenamento.

$\mathrm{Na}$ temperatura de $15^{\circ} \mathrm{C}$, nas três embalagens avaliadas, houve incremento do teor de vitamina $\mathrm{C}$ até o sétimo dia, obtendo máximo teor de $48,5 \mathrm{mg} / 100 \mathrm{~mL}^{-1}$ utilizando a embalagem saco plástico. Para $25^{\circ} \mathrm{C}$, a embalagem bandeja isopor apresentou máximo teor de $46,8 \mathrm{mg} / 100 \mathrm{~mL}^{-1}$ no sexto dia de armazenamento. Para as outras embalagens, não foi ajustado regressões devido à alta variação durante as avaliações, apresentando valores médios de 36,41 e 36,13 mg/100 $\mathrm{mL}^{-1}$ para a bandeja pet e saco plástico, respectivamente.

\section{Conclusões}

Com base nos resultados recomenda-se que o repolho minimamente processado seja utilizado até o oitavo dia do processamento; que seja utilizado como embalagem a bandeja pet e armazenado em temperatura de $15^{\circ} \mathrm{C}$. Nessas condições houve moderada perda de massa e manutenção dos teores de sólidos solúveis totais, vitamina $\mathrm{C}$, acidez titulável e $\mathrm{pH}$

\section{Agradecimentos \\ A FUNDECT e Capes, pela bolsa concedida.}

\section{Referências Bibliográficas}

CANTWELL, M.; SUSLOW, T. V. Postharvest handling systems: minimally processed fruits and vegetables. In: KADER, A. A. Postharvest technology of horticultural crops. California: Division of Horticultural and Natural Resources, 2002. p. 445-463.

CHITARRA, M. I. F.; CHITARRA, A. B. Pós-colheita de frutos e hortaliças: fisiologia e manuseio. $2^{\circ}$. ed. Lavras-MG: Editora UFLA, 2005. 785 p.

EMPRESA BRASILEIRA DE PESQUISA AGROPECUARIA. Processamento mínimo de frutas e hortaliças: tecnologia, qualidade e sistemas de embalagem. Rio de Janeiro-RJ: Editora Embrapa, 2011. 144 p.

GIOPPO, M.; SOUZA A.M.; GONÇALVES, J.; AYUB, R. A. Vida útil pós-colheita do repolho roxo minimamente processado, armazenado em diferentes embalagens. Revista Ceres, Viçosa-MG, v. 59, n. 4, p. 560-564, 2012. 
IAL. INSTITUTO ADOLFO LUTZ Normas Analíticas do Instituto Adolfo Lutz: Métodos químicos e físicos para análise de alimentos. $2^{\mathrm{a}}$ ed, São Paulo-SP: Instituto Adolfo Lutz, 1985. 371p.

JACXSENS， L.; DEVLIEGHERE， F.; DEBEVERE， J. Predictive modelling for packaging design: equilibrium modified atmosphere packages of fresh-cut vegetables subjected to a simulated distribution chain. International Journal of Food Microbiology, Amsterdam-NL, v. 73, n. 1, p. 331-341, 2002.

KAWANO, S.; ONODERA, T.; HAYAKAWA, A. Cold storage of shredded cabbage. Report of the National Food Research Institute, Ibaraki-JP, v. 45, n.1, p. 86-91, 1984. Disponível em: < http://www.scielo.br/scielo.php?pid=S010120612009000200012\&script=sci_arttext $>$. Acesso em: 15 set. 2015.

KLEIN, B.P. Nutritional consequences of minimal processing of fruits and vegetables. Journal of food Quality, United Kingdom-USA, v. 10, n. 3, p. 179-193, 1987.

KLUGE, R. A.; NATCHTIGAL, J. C.; FACHINELLO, J. C.; BILHALVA, A. B. Fisiologia e Manejo Pós-Colheita de Frutas de Clima Temperado. Campinas-SP: Editora Rural, 2002. 214 p.

LUENGO, R. F. A.; CALBO, A. G. Armazenamento de hortaliças. Brasília-DF: Embrapa Hortaliças, 2001. 242 p.

RINALDI, M. M.; BENEDETTI, B. C. Influência da Embalagem de polietileno de baixa densidade e da temperatura na conservação do repolho minimamente processado. Engenharia Agrícola, Jaboticabal-SP, v. 24, n. 2, p. 412-420, 2004.

RINALDI, M. M.; BENEDETTI, B. C.; CALORE, L. Efeito da embalagem e temperatura de armazenamento em repolho minimamente processado. Ciência e Tecnologia de Alimentos, Campinas- SP, v. 25, n. 3, p. 480-486, 2005.

RINALDI M. M.; BENEDETTI B. C.; SARANTÓPOULOS C. I. G. L.; MORETTI C. L. Estabilidade de repolho minimamente processado sob diferentes sistemas de embalagem. Ciência e Tecnologia de Alimentos, CampinasSP, v. 29, n.2, p. 310-315, 2009.
ROURA, S. I.; DAVIDOVICH L A.; DEL VALLE, C.E. Quality loss in minimally processed swiss chard related to amount of damaged area. Lebensmittel Wissenschaft und Technology, Argentina-AR, v. 25, n. 9 p. 23-53, 2000.

SANTOS, J. S.; OLIVEIRA, M. B. P. P. Revisão: alimentos frescos minimamente processados embalados em atmosfera modificada. Brazilian Journal of Food Technology, Campinas-SP, v. 15, n. 1, p. 1-14. 2012

SANTOS, T. B. A.; SILVA, N.; JUNQUEIRA, V. C. A.; PEREIRA, J. L. Microrganismos indicadores em frutas e hortaliças minimamente processadas. Brazilian Journal Food and Technology, Campinas-SP, v. 13, n. 2, p. 141-146, 2010.

SILVA, M. Z. T.; GUERRA, N. B. Avaliação das condições de frutos minimamente processados. Higiene Alimentar, São Paulo-SP, v. 17, n. 111, p. 29-36, 2003.

SOARES, L. R.; PEREIRA, D. C.; MONTEIRO V. H.; SOUZA, C. H. W.; KLEIN, M. R.; SILVA, M. J.; LORIN, H. F.; COSTA, L. A. M. \& COSTA, M. S. S. Avaliação de substratos alternativos para produção de mudas de repolho. Revista Brasileira de Agroecologia, Pelotas-RS, v. 4, n. 2, p.1780-1783. 2009.

TELES, C. S.; RAMOS, A. M.; GERALDINE, R. M., STRINGHETA, P. C.; VILLADIEGO, A. D.; PUSCHMANN, R. Evaluación de las alteraciones químicas, físicas y sensoriales en col (Brassica oleraceae, var. acephala) mínimamente procesad conservada sobre atmósfera modificada. Alimentaria: Revista de tecnología e higiene de los alimentos, Espanha, v. 363, n. 3, p. 112-117. 2005.

WILlEY, R. C. Frutas y Hortalizas Mininamente Processadas y Refrigeradas. Zaragoza-ESP: Acríbia. 1997. $362 \mathrm{p}$. 